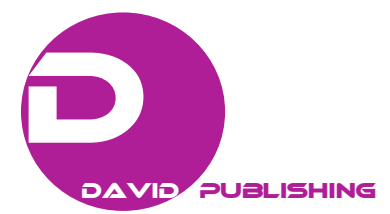

\title{
The Biodiversity of Cyprus Island
}

\author{
Alessandro Lentini \\ Italian National Research Council-Institute for Technologies Applied to Cultural Heritage, Rome 00016, Italy
}

\begin{abstract}
The aspects considered in this paper refer to remains of food plants found in the archaeological area of Pyrgos (Early Bronze Age, 2000 B.C.) near Limassol in Cyprus, related to the history of agriculture and cultivated plant processing technologies. For the purposes of an initial comparison of the archaeobotanical data, the authors updated a map of rainfall distribution on Cyprus with rainfall and temperature data for the period from 1973 to 2007, to produce an updated view of possible microclimates on the island. Cyprus was one of the Mediterranean islands whose particular orographic features encouraged the phylogenetic evolution of many species, and today it is especially rich in endemic species. Cyprus located at the southeastern boundary among the Mediterranean region, the Pontic region (the Irano-Turanic element) and the Near East (the Syriac and Nubo-Sindic elements) it doesn't seem to have effectively influenced the most important endemic species, they were probably preserved by the island's microclimates and particular edaphic conditions.
\end{abstract}

Key words: Biodiversity, Cyprus, geobotany, archaeology, seeds macroremains, Mediterranean basin.

\section{Introduction}

The aspects considered in this paper refer to remains of food plants related to the history of agriculture and cultivated plants. Various crop microremains (Triticum dicoccun, Triticum monococcum, Triticum durum, Hordeum distichum, leguminose Cicer arietinum, Lens culinaris MEDIK, Lens culinaris ssp. orientalis, Pisum sativum L.), olive and grape wine, were found in the past in the different archaeological sites in Cyprus. The same microremains have been reported at the sites of Shillourokambos, dated 9000 B.C.; Cape Andreas Kastros, dated 7000 B.C.; Khirokitia, same period as Cape Andreas; and the Middle Bronze Age sites of Marki Alonia and Pyrgos Mavrorachi [1]. These findings show how highly advanced were the different methods of cereal cultivation and selection. In parallel, the ecological approach entailed analyzing the paleocarpological finds in order to define the environment in which prehistoric agriculture was able to develop. These microremains raise a series of environmental questions regarding the geographic

Corresponding author: Alessandro Lentini, geobotanist, Italian NRC's archaeological mission at Pyrgos, Cyprus. E-mail: alessandro.lentini@itabc.cnr.it. distribution of crops, leguminous, olive trees and grape wine in Cyprus (biogeography), biodiversity in the natural landscape, and species imported or partially domesticated adapted by human activities. In this context, the oldest plant macro remain seems to belong to the least defined probable biodiversity levels [2]. In effect, it is very hard to judge biodiversity in archaeological contexts, mainly due to the fact that no certified method exists for classifying these paleo environmental structures, because the principal recognizable units represent different sectors of a highly variable anthropized environment.

Archaeobotanical, paleopalinological and sedimentological investigations plus exploration in the areas adjacent to the Pyrgos Mavrorachi site [3] have evidenced a series of environmental discontinuities that make up Cyprus's natural landscape.

\section{Materials and Method}

\subsection{Geography of the Island}

The island of Cyprus is the third largest island in the Mediterranean Sea due to its dimensions. It is located in (Fig. 1) south of Turkey, a short distance from the coast of the Near East and about $500 \mathrm{~km}$ from the coast of Egypt, west of Syria and Lebanon, 


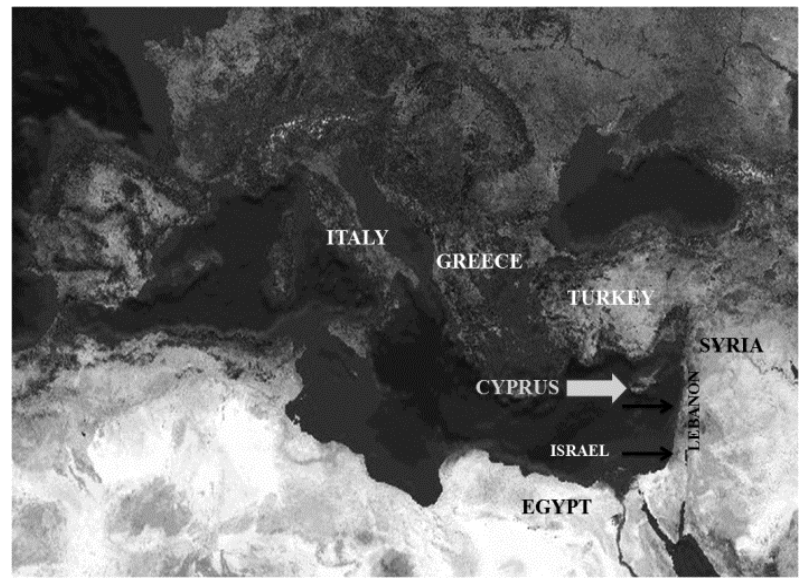

Fig. 1 Geographical position of the Cyprus island.

and northwest of Israel. Cyprus is 240 kilometers long and $100 \mathrm{~km}$ (62 mi) wide.

In historical/cultural terms, Cyprus could be considered as a European state, from the geographical point of view according to the method for which a territory belongs to a continent for its geographical proximity, the island it is part of the Asia Minor. One can referred Cyprus as a European country or as an Asian Minor state, depending on the criteria adopted.

The characteristic shape of a pan of Cyprus reflects its geomorphologic features. To the north extends the mountain range of Kyrenia (Girne), about $100 \mathrm{~km}$ long, which runs parallel to the northern coast.

This chain, the southernmost among those who constitute the great Alpine-Himalayan belt, consists of Mesozoic limestone. To the south of the Kyrenia Mountains begins the vast plain of Mesoaria (Mesarya), which extends from the west of Morfou to east of Famagusta. In the southern (south-west) is the largest mountain range in Cyprus, located in the center of the island. Tröodos' highest peak is Mount Olympus at 1,953 meters or $6,404 \mathrm{ft}$. While, to the east starts a lowland that slopes towards the sea up to the Akrotiri peninsula. The rivers that have a regular flow system regime are the Yialias and the Peidos, and both are about $100 \mathrm{~km}$ long. The Mediterranean climate is characterized by a pronounced seasonality: the summers are very hot and dry and they last on average from mid-May to September, while winters have a variable trend with alternating cold periods myths according to the altitude and distance from the sea, usually in the winter you can find the Troödos Mounts snowy. The transition period between autumn (mid October) and spring (March-mid May) is moderately short according to measurements of meteorological. The distribution of rainfall during the autumn and winter is related to the orography of the territory, with a maximum average above $1,000 \mathrm{~m}$ of $900 \mathrm{~mm}$ and average minimum in the vicinity of the coastline of 300-400 $\mathrm{mm}$. Therefore, the problem of water scarcity in Cyprus is very important. The vegetation of the island is not easily detectable at first sight for the marked seasonal pattern. In summer the island is very arid, some areas (plain Mesoaria and the district of Morphou) are almost desertified while certain areas are characterized by sclerophyllous evergreen in the vicinity of rivers and floodplains. During the short spring one can see the manifest of characteristics of the different environments of a floristic Cyprus, with the flowering of an endemic wild. With its approximately 1,800 species and subspecies of flowering plants which about 179 autochthonous. The vegetation is spread over eight micro habitats that divide the island by geographical barriers and abiotic elements. The important areas to indigenous species are the Cedars valley, the Troödos massif and their western offshoots to the Paphos forest near the sea. They have been identified and described 45 species of orchids and one of them the Cyprus Bee Orchid (Ophrys kotschyi) and the rare Ranuncolacea (Delphinium caseyi B.L. BURT) hat only blooms on this island. The vegetation of Cyprus is as in other Mediterranean distribution area, the consequence of the pulsations of the Quaternary glaciations, when native species of continental Europe took refuge in the territories bordering the Mediterranean Sea.

\subsection{Method}

Geobotanical investigations began with a series of surveys around the archaeological site of Pyrgos 
Mavrorachi. From the geological standpoint, Pyrgos is in the southern coastal belt under the slopes of the Troödos massif, which stretches from the peninsula of Akrotiri (Gulf of Limassol) to the Gulf of Larnaca, and includes a large mining area. For the purposes of an initial comparison of the archaeobotanical data, the authors updated a map of rainfall distribution on Cyprus [4] with rainfall and temperature data for the period from 1973 to 2007, to produce an updated view of possible microclimates on the island. These data were collected from 25 weather stations (Fig. 2) located irregularly across the island, some concentrated in the central part (the Mesaoria plain, from Nicosia to Famagosta), others on the West coast (from Morocampos to Episcopi) and still others near the heights of the Troödos mountains (from Platania to Trimiklini), with significant absences in the North East, the North West and on the southern coast. The weather data were processed with the aid of the Köppen formula [5]:

$$
I_{a}=\frac{1}{2}\left[\frac{P_{1}}{T+10}+\frac{12 P_{2}}{t}\right]
$$

The Köppen climate classification system uses mean monthly and annual values of temperature and precipitation to classify climates.

$$
\begin{aligned}
& \mathrm{P}_{1}=\text { rainfall in } \mathrm{mm} ; \\
& \mathrm{P}_{2}=\text { average rainfall in the driest month; } \\
& \mathrm{T}=\text { average annual temperature }\left({ }^{\circ} \mathrm{C}\right) \mathrm{t}=\text { average }
\end{aligned}
$$

temperature in the driest month.

Indexes $<10=$ arid climate.

Indexes between 10 and $20=$ subarid conditions .

Indexes between 20 and $30=$ subhumid conditions .

\section{Results and Discussion}

The updated climate data processed on the basis of contour lines obtained from cartographic elements reported in the past [4] showed a distribution in eight microclimates that reflected the island's geological and altimetric features. In fact, some areas are marked off by geographic barriers (the Troödos and Kyrenia mountains) and their characteristics of their plant

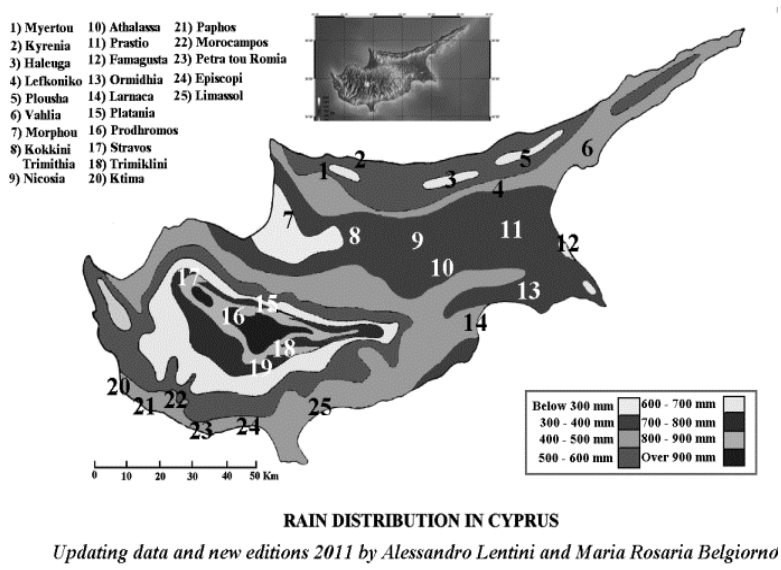

Fig. 2 Rain distribution and the eight biomes in Cyprus.

populations are allopatric, while others are marked off by abiotic factors (climatic elements and soil characteristics) that operate in the same geographic area with various sympatric plant species. On the northern side of the island, The Kyrenia mountains is a long, narrow mountain range that runs for approximately $160 \mathrm{~km}(100 \mathrm{mi})$ along the northern coast of the island.

The Kyrenia mountains are the Southernmost part of the Alpine-Himalayan range; they are made up mainly of Mesozoic limestone and are characterized by low precipitation and thermoclastic phenomena. The Kyrenia rocks have low thermal conductivity values [6], which explain why large temperature differences occur between their outer and inner parts, generating stress that causes the rocks to crumble. Three microclimates were identified in this area (Fig. 2), and are also found beyond the Mesaoria plain. The most extensive one, referable to the Kyrenia weather station (Fig. 2), includes the mountainous area that slopes down to the sea, and is characterized by soils consisting for composed of the most part of Dolomitic limestone with a high degree of salinity. Here the most representative biome is made up of Juniperus phoenicea L. (the Syriac element) and various seasonal halophytes, while Pinus brutia is presented at the medium to high altitudes.

The second microclimate, referable to the Haleuga station (Fig. 2), is divided into three small areas, 


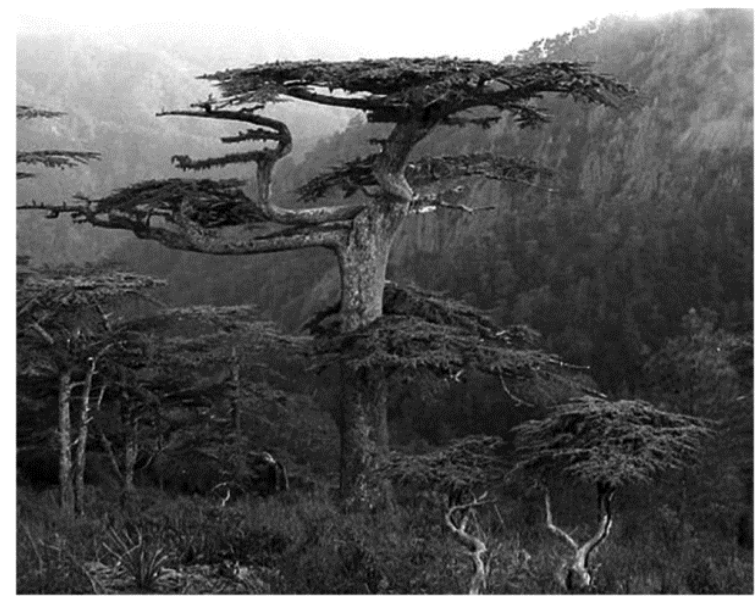

Fig. 3 Cedar Valley, Cedrus brevifolia Hook.f..

distant from each other, at the highest altitudes in the Kyrenias; here the ground is rocky (sub-acid limestone) and there is no significant stable vegetation.

The third microclimate characterizes a large area with allopatric features, the northwest-northeast area between Kormakiti and the tip of Cape Andreas. It is monitored by only one weather station, at Vahlia (Fig. 2). It is separated from the rest of the distribution of belonging to the south and south-east from the plains of Mesaoria, north-west from the desertified area of Morphou in the south of the island and to the south-west by the foothills of the mountains Tröodos sloping down to the sea. Almost all the weather stations covering this microclimate are located along the coasts: at Ktima, Paphos, Morocampos, Patria tou Romiou and Episcopi in the South West (Fig. 2), near Limassol in the South (Fig. 2), and at Larnaca in the South East (Fig. 2). Generally speaking, the soils in these areas have a medium texture; in the more internal areas they have high carbonate content and are subject to frequent leaching phenomena, while in the areas adjacent to the coastline they are characterized by high percentages of sodium and potassium. The native vegetation is consists of Irano-Turanic species (Cupressus sempervirens L., Pinus halepensis Mill. and Cedrus brevinfolia Hook.f.) and Mediterranean species (Prunus, Pistacia, Olea europea L., Quercus, Ceratonia, Myrtus and Laurus) variously distributed across the territory according to local variables [7].
Growing near the short streams are Popolus, Salix, Miriophyllum and other aquatic grasses.

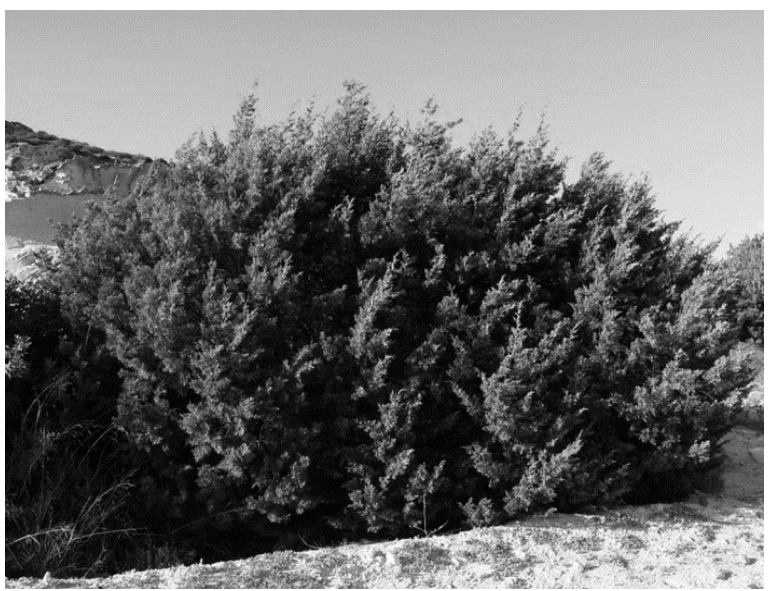

Fig. 4 Akrotiri bay, Juniperus phoenicea L..

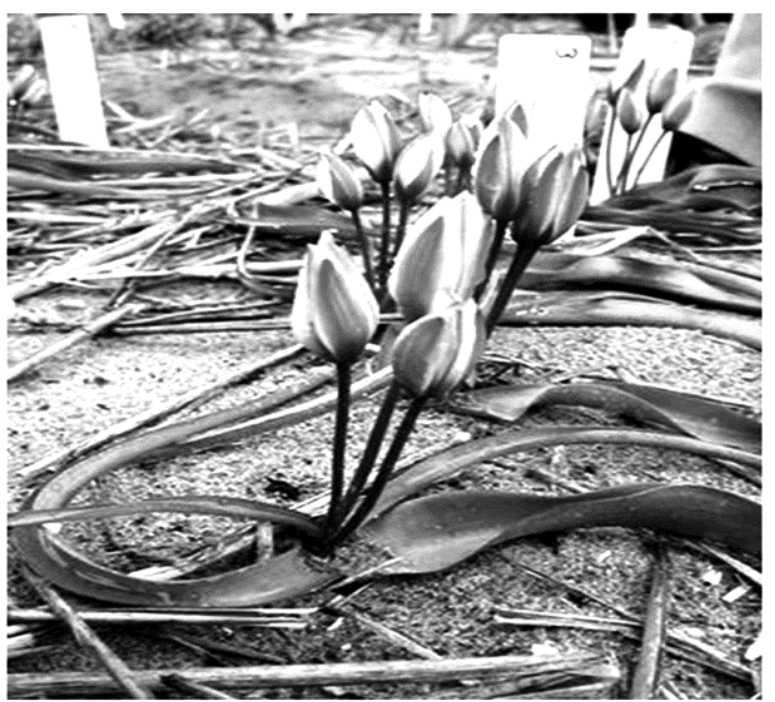

Fig. 5 Elias bridge Kaminaria, Tulipa cypria.

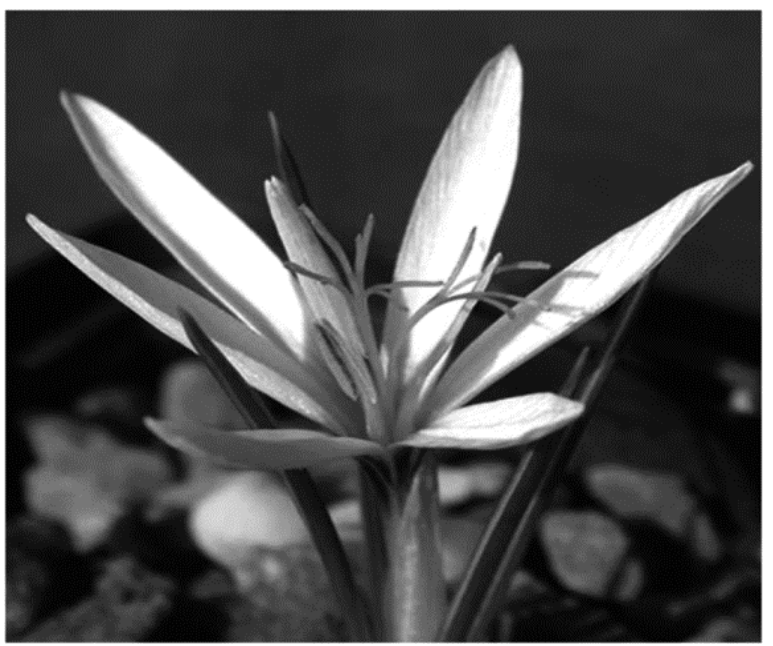

Fig. 6 Troödos mountains, Crocus veneris. 


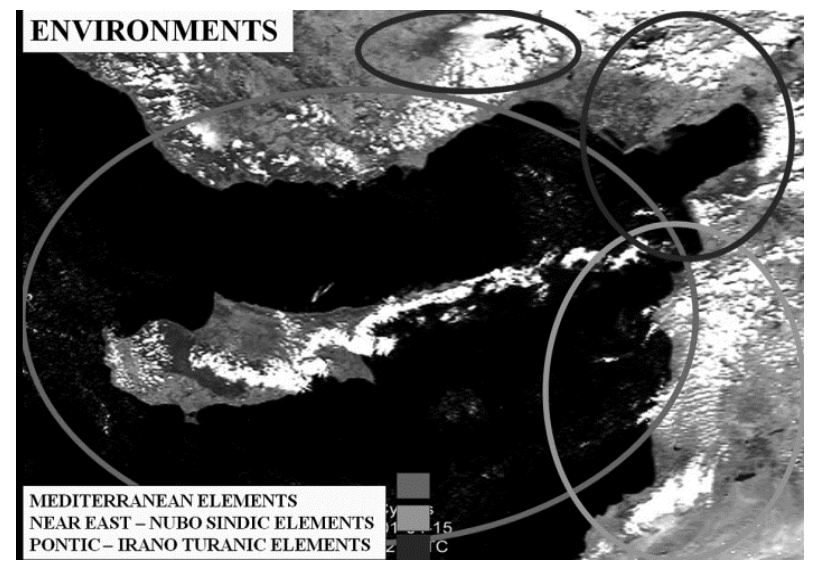

Fig. 7 Distribution of the different vegetation elements on the border between the Mediterranean area and the Near East.

The fourth microclimate, with less than $300 \mathrm{~mm}$ of rainfall per year, according to the data reported by the Morphou weather station (Fig. 2), is the island's only desertified area. As the soil is made up of calcareous sands with a high degree of salinity, it is subject to evapotranspiration phenomena. The vegetation that grows here during short periods of the year consists of halophytes (Chenopodiaceae, Amaranthaceae and Salsola ssp.). The fifth microclimate is one of the largest of the island, it includes the Mesaoria plain, which has the highest concentration of weather stations, at Kokkini Trimithia, Nicosia, Athalassa, Prastio and Famagosta (Fig. 2). This territory, nearly all irrigated and farmed, is the one that has been most intensely affected by human activities over the course of history. This area has a high rate of deforestation, fires and farming methods that have eroded and depleted the soils, with the formation of a garrigue associated with anthropocore species, mainly Quercus coccifera, Olea europea L., Olea europea L. var. sylvestris (wild olive), Ceratonia ssp. (carob), Graminaceae, Genista ssp., Calycotome ssp., Chenopodiaceae-Amaranthaceae,

Asteraceae, Labiatae and Compositae. The garrigue is the next to last stage in the regression of Mediterranean phytoclimatic associations, after the Oleo-Ceratonion xerophile scrub and before the steppe. Its widespread presence in a Mediterranean region can be taken as an indicator of desertification.

In this microclimate, there are also some wetlands that are considered marginal, including streams and lakes near Famagosta. They are characterized by associations of halophytes (Juncus ssp., Spartina ssp., Salicornia fruticosa and Arthrocnemum fruticosum). In this range, there is a disjunction toward the southeast, near the border between Kiti and Larnaca. In the spring, the vegetation here consists mainly of Ulva ssp., Enteromorpha ssp. and Chaetomorpha ssp.

The other three microclimates are located in the Troödos mountains at altitudes between 1,600 and 1,900 meters, and on up to the highest peak of Mt. Olympus (1,952 meters). They are monitored by weather stations at Platania, Prodhromos, Stravos, Trimiklini and Lania (Fig. 2). The limestone foothills are subject to Karst phenomena, with the formation of dolines and sinkholes. Sandstone and conglomerates are presented in some parts of these areas. The vegetation on these lower slopes consists of evergreens (Cupressus sempervirens and Juniperus phoenicea), semi-deciduous trees (Quercus coccifera and Quercus infectoria) and Arbutus andrachne. Along the streams that flow down from the higher altitudes are large riverside forests composed of Popolus, Salix and Alnus. At the lowest altitudes, near the sea, the beds of these streams usually remain dry during the spring and summer. At altitudes of around 900-1,000 meters, Vitis vinifera L. ssp. sativa Hegi is cultivated on manmade terraces with the "little tree" method. The vines, each one set in a small hollow that protects the grapes from the hot winds, are pruned to a height of 30-40 centimeters. A few "branches" grow on each "tree," each branch is left with one or more shoots, each shoot with one or two buds. The territories lying above 1,000 meters in the Troödos mountains are composed of igneous formations and pillow-lava, originating from molten magma that flowed into the sea during the drift of the Eurasian plate from the Arabian plate. The biome which can most representative of these areas are the vast pine 
woods, are made up mainly of Pinus brutia and the endemic species Cedrus brevifolia Hook.f. (Fig. 3), associated with Quercus alnifolia, likewise an endemic species. At the higher altitudes near Mt. Olympus are Pinus palladiana woods, with Juniperus foetidissima Willd presented in the glades (Fig. 4).

The pine forest was Cyprus's original biome, and in the past it probably covered a large part of the island [9]. At present, this biome occupies some residual areas near Paphos (at sea level), as well as the areas at the highest altitudes. In the past, human activities and climate changes seem to have drastically impoverished the original biome [3]. Overall, the vegetation on Cyprus, as in other Mediterranean areas, is the result of glacial movements in the Quaternary era, when species native to continental Europe retreated to territories on the Mediterranean Sea. Besides furthering the preservation of these northern species, the Mediterranean areas became the evolutionary environments of individual species [10]. Cyprus was one of the Mediterranean islands whose particular orographic features encouraged the phylogenetic evolution of many species, and today it is especially rich in endemic species [11]. Endemisms are widespread on many Mediterranean islands (Sardinia, Corsica, Sicily, Malta, Cyprus, Crete, Zakynthos), where conditions are favorable for speciation, due to the presence of geographic and abiotic barriers that hinder dispersion of the original genetic makeup. They are especially numerous on the islands that have been separated longest from the mainland. The great diversity of habitats and microclimates on Cyprus makes for an abundance of native species. Their numbers are estimated at 179 [11], and their distributions range from the Troödos mountains (87) to the Kyrenias (57) and the Akamas peninsula (35). Systematic botanists consider some of them, such as the Cyprus cedar (Cedrus brevifolia Hook.f.) and the Cyprus oak (Quercus alnifolia) to be living fossils [11]. The aromatic species Nepeta troodi, Teucrium cyprium, Teucrium micropodioides, Thymus integer, Salvia willeana and Origanum cordifolium are thought to be among the major evolutionary lines of the officinal species that are most widespread and best known in the Mediterranean region. Species bulb Cyclamen cyprium, Tulipa cypria, Crocus cyprius, Crocus veneris, Chionodoxa lochiae and Gagea juliae, particularly rare [12], were in some cases used as medicinal plants and in the past also drawn on pottery, mosaics, glass and other objects of artistic value (by Dioscoride in De Materia Medica, Codex Julianae Aniciae). Cyprus is located at the southeastern boundary the Mediterranean region (Fig. 7), the Pontic region (the Irano-Turanic element) and the Near East (the Syriac and Nubo-Sindic elements) [13] does not seem to have effectively influenced the most important endemic species, and they were probably preserved by the island's microclimates and particular edaphic conditions.

\section{Conclusions}

The analysis of the seeds of the various species of Vitis found at Pyrgos, taking together with the results of the sedimentological and paleopalinological tests, indicates that optimal conditions existed for the cultivation of Vitis at low altitudes (100-200 m) near the sea (4 $\mathrm{km}$ away), in an environment very different from the one in which Vitis vinifera L. ssp. sativa hegi is cultivated today on the slopes of the Troödos mountains, at much higher altitudes (900-1,100 meters). The preliminary results obtained at Pyrgos suggest that the local climate was cool and moist, also observed in other sites of the southern Mediterranean dated from 1900-2000 BC [14-19]. In those environmental conditions, when the climate was cool and moist, the vegetation now found at medium and high altitudes likely grew at lower altitudes closer to the sea. later on, due partly to the evolution of the climate and the environment in all the Mediterranean territories toward sub-arid periods [20], and partly to increasingly intense human activities, the most representative biocenoses gradually moved to higher 
altitudes, where the environmental conditions were still cool and moist.

\section{References}

[1] Adams, R., and Simmons, R. D. 1996. "Archaeobotanical remains." In Marki Alonia, an Early and Bronze Age Town in Cyprus, edited by Frankel, D., and Webb, J.M. Jonsered: P. Åströms Förlag.

[2] Medail, F., and Quezel, P. 1997. "Hotspots Analysis for Conservation of Plant Biodiversity in the Mediterranean Basin.” Annals of the Missouri Botanical Garden 84 (1): 112-127.

[3] Lentini, A., and Belgiorno, M. R. 2008. "Archaeobotanical Investigations at Pyrgos-Mavrorachi (Cyprus), Preliminary Results" In Proceedings of the IV International Cyprological Congress, edited by Demetriou, A. Nicosia: Leventis Foundation.

[4] Zohary, M. 1973. Geobotanical Foundation of the Middle East. vols. 2. Amsterdam: Swets and Zeitlinger.

[5] McKnight, T. L., and Hess, D. 2000. "Climate Zones and Types: The Köppen System." Physical Geography: A Landscape Appreciation 1 (1): 200-201.

[6] Malikkides, C. 2006. "Calculation Methods for Critical Loads of Acidity and Nutrient Nitrogen and for Dynamic Modelling." Bulletin of Ministry of Labour and Social Insurance 2 (1): 1-6.

[7] Meikle, R. D. 1985. Flora of Cyprus. Kew: Royal Botanical Gardens.

[8] Gomez Campo, C. 1985. Plant Conservation in the Mediterranean Ecosystems. Geobotanica 7. Dordrecht: Junk Publishers.

[9] Quezel, P. 1979. "Les Ecosystemes Forestiers Crétois et Chypriotes." Revue Forestière Française XXXI (5): 440-450.

[10] Strasburger, E., Noll, F., and Schenck, H. 1990. Sistematica Geobotanica. Roma: Delfino Editore.
[11] Pantelas, V., Papachristophorou, T., and Christodoulou, P. 1993. Cyprus Flora in Color: The Endemics. Nicosia: Kailas Printers.

[12] IUCN, Centres of Plant Diversity. 1994. A guide and strategy for their conservation. vol. 3. Cambridge: IUCN Publication Service Unit.

[13] Zohary, D. 1996. "The Domestication of the Grapevine Vitis Vinifera L. in the Near East." In The Origins and Ancient History of Wine, edited by McGovern, P.E. Amsterdam: Gordon and Breach Publishes.

[14] Palmieri, A. M. 1980. "Studio Sedimentologico Del Saggio Profondo Di Coppa Nevigata (Gargano)." Quaternaria XXII (2): 301-313.

[15] Belluomini, G., Esu, D., Manfra, L., and Matteucci, R. 1980. "Gasteropodi Dulcicoli Terrestri Nell Isola Di Dahlak Kebir-Testimonianze Di Una Fase Umida Olocenia Nelle Isole Dahlak, Mar Rosso." Boll. Malacologico 16 (1): 369-390.

[16] Bar-Yosef, O. 1990. "The Last Glacial Maximum in the Mediterranean Levant." In The World at 18,000 BP. Edited by Soffer, O., and Gamble, G. London: Unwin Hyman publishers.

[17] Lentini, A., and Palmieri, A. M. 1993. "Test Sedimentologico Nel Sito Di Tharros." Rivista Studi Fenici XXI: 183-190.

[18] Palmieri, A. M., Lentini, A. 1994. "Indagini Paleopalinologiche Fisico Chimiche Nel Quadrante Meridionale Della Sponda Ovest Dello Stagno Di Cabras." Rivista Studi Fenici XXII (2): 195-200.

[19] Rögl, F. 1999. Oligocene and Miocene Palaeogeography and Stratigraphy of the Circum-Mediterranean Region. edited by Whybrow, P. J., and Hill, A. vol. I. New Haven: Yale University Press, 485-500.

[20] Barbero, M., and Quezel, P. 1979. “Contribution á Létude Des Groupements Forestiers De Chypre." Documents Phytosociologiques 4 (1) : 427-459. 